\title{
Stitching Together: ethical dimensions and innovative approaches to participatory textile making
}

Emma Shercliff

Arts University Bournemouth, UK

Amy Twigger Holroyd

Nottingham Trent University, UK

Keywords: participatory textile making, ethical dimensions, communication, (re)presentation, innovation, vulnerabilities, co-production of knowledge

\section{Introduction}

This is the second part of a double special issue of the Journal of Arts and Communities generated through the work of the Stitching Together research network. ${ }^{1}$ The network has gathered together researchers, project commissioners, professional textile practitioners and enthusiast maker groups with the overarching aim of fostering critical dialogue around participatory textile making methods in research and practice. Two events have allowed us firstly to establish key characteristics of these participatory making activities, and secondly to interrogate the validity and effectiveness of these new methodological approaches within research contexts. A dedicated website records network activities, showcases work by network members, and allows the network to reach audiences beyond those able to attend the UK-based events.

The eight articles published in the first issue presented a range of projects that explore participatory textile making as a means, and sometimes the subject, of research. In our introduction to that issue we highlight important methodological aspects of this work, including the complex and interrelated ethical and practical considerations involved in the undertaking of participatory textile projects. The case studies introduce relevant theoretical lenses that can be used to frame participatory textile making as research, and some demonstrate how established methodologies found in other research fields can be adapted to work within these new research contexts. As we observe, the 'person-oriented'2 characteristics of these participatory textile making activities centre around the relationships and roles adopted by the facilitators, researchers and participants; the textile making itself; and the (co-)production of knowledge that the activities make possible. 
Yet with the (co-)production of knowledge comes a responsibility to tell the stories of participation respectfully - a responsibility that raises questions about hierarchies of knowledge holders, ownership and (re)presentation. In addition, while keeping in mind the creative motivations behind many of these making activities, it is important to consider the ethical dimensions of aesthetics and innovation - for example, on what basis is the work innovative, and for whom?

In this introductory article, we outline some of the ethical dimensions of participatory textile making in greater depth and discuss the nature of innovation within this research context. Insights drawn from discussions held at the second network event ${ }^{3}$ help to frame and connect key themes running through the case studies presented in this second issue. To begin, we address the important issue of inclusivity; it is crucial for all members of a participatory textile making group - participants, researchers, facilitators, practitioners and other partners - to feel included in the activities on terms they are comfortable with. For a successful knowledge-generating activity to be as inclusive as possible, it will necessarily challenge the habitual practices of participants, of researchers, of organisations and of spaces. The acknowledgement of real or perceived vulnerabilities in a project or a practice, or an individual, is an important step towards creating opportunities for critical investigation. This acknowledgement highlights the essential role of communication, and we go on to explore ways of communicating with participants and partners during the projects, before considering the (re)presentation of project and participants within the research findings. Finally, we address the innovative approaches mentioned in our title. By questioning for whom the activities are innovative, we trouble accepted ideas around innovation as creative invention of product, tool or process to focus on the experience of being involved in the designing and making of textiles.

[insert Figure 1 here]

\section{Vulnerabilities: making space for shared learning}

Underlying the potential for the (co-)production of knowledge is a requirement for humility and a readiness to accept flaws and limitations. Humility makes room for a shared learning space and allows for a critical questioning of habits and perceptions. However, this can render a project and those involved in it vulnerable.

A common theme across many of the discussions held at the second network event concerned how best to manage the issues arising from our vulnerabilities. Prospective participants, for example, might feel a sense of heightened vulnerability on entering an 
unfamiliar space. This sense might be triggered by an uncertainty about the demands made of them by a research space, or, if unfamiliar with a particular making activity, it could be the perceived threat of a space convened for such an activity. For the facilitator, or the researcher, the move from the familiar space of the studio to an unfamiliar setting can be equally disarming, leaving an otherwise confident practitioner feeling ill equipped to consider appropriately their own physical safety or emotional well-being. Overlooking these imbalances and assuming levels of ability, willingness and preparedness to engage in participatory making activities exposes an unconscious bias that is likely to distort the nature and quality of the experience of being involved in the making activity (Kara 2018). The (co)production of knowledge therefore necessitates an awareness that each individual involved in the project is, on some level, undergoing these transitions.

Many of the articles in this issue demonstrate how both recognising these vulnerabilities and opening a humble space for shared learning can reap benefits for the project: from settings where severe illness overshadows the task (Rana), through to unemployment (Taylor et al.), and the lack of stitching skills (Setterington). Each of these case studies discusses ways of involving participants who because of their perceived vulnerabilities - whether associated with gender, age, ability or social position - might conventionally be excluded from joining in. Setterington discusses Threads of Identity, a collaborative project with secondary school boys at Burnage Academy for Boys in Manchester that used the tradition of embroidering signatures to commemorate friendship, in turn connecting young boys to their own sense of identity through their newly gained sewing skills. Rana explores in detail the collaboration between a mother suffering from dementia and her daughter-carer as the activity of knitting together reaches into a past forgotten or unknown. Taylor et al. describe how HUGs $\AA_{\text {, a }}$ 'social manufacturing' project (Hamalainen \& Karjalainen 2017) involving a small group of long-term unemployed women in a deprived area of Port Talbot in South Wales, introduced opportunities for training and personal development that supported participants' well-being.

\section{Communication}

Crucial to this open and productive research space is the way in which researchers, facilitators and participants communicate. In our introduction to the first issue we describe how the textile making activity "occupies the mind, body and senses in a subtly dynamic engagement with materials and place and prompts unforeseen connections that cannot necessarily be put into words eloquently" (Shercliff \& Twigger Holroyd 2020: 14). There are likely to be different modes and formats of communication in use within a participatory textile making project, and these are often happening concurrently rather than distinctly: verbally, 
using language to provide information and instruction as well as conversation; artistically and graphically, through the sharing of imagery or use of diagrams; and more subtle, non-verbal and non-visual means of communication through physical gestures, facial expressions and bodily interactions.

On one hand these multiple modes of communication make the observation of rich material and social interactions within a group possible. Rana's study highlights this in particular, focusing on the use of video as an aide memoire that enables researcher and participant to return to the original footage to examine overlooked actions and gestures together. On the other hand, clear instruction or expressions of discomfort can be subsumed into a melée of bodies, tools and materials during the making activity. There is a risk that dominant views on how to execute a task 'correctly' slip may to the fore unchecked, or that aesthetic priorities overshadow the distinctiveness of each individual's making, potentially leading participants to question the value of their contribution. Articles here highlight the ways that, again, an acknowledgement of these vulnerabilities in the research space can lead to the dismantling of barriers and greater engagement in the project. In their article Townsend and Sadkowska discuss how the limitations of an initial study, which failed to fully engage participants in communication about the research with the researcher, prompted the development of a robust and transferable model for engaging with participant groups in their second study: Emotional Fit. Wong and van den Berg discuss two craft projects - yarn-bombing and quiltmaking - that brought together disparate communities in Harlem, both long-established and new to the area, to help dislodge preconceived ideas about participation in the arts. It is interesting to note that this was in part achieved through the creation of a 'living' memorial, which introduces questions of display and representation to which we will return below.

These examples make use of the ways in which participatory making facilitates conversation within a group. However, others advocate for the quiet power of non-verbal communication embedded within textile-making processes. In her article, MacDowell demonstrates how participants joining the Teal Quilt Project harnessed patchwork quilt-making techniques to express both outrage at the sexual abuse crimes committed by Larry Nassar at Michigan State University and compassion for the survivors. The translation of these powerful emotions into graphic patterns made of fabric conveys a sense of connectedness and empathy that demonstrates a capacity of cloth and textile making to surpass the use of words (Pajaczkowska 2005). The makers of these patchwork quilts express non-verbally their sensitivity to the lived experiences of these women in pursuit of a sense of collective healing. 


\section{Display: (Re)presentation: Ownership}

The politics of (re)presentation must be a core concern of participatory textile making projects. Indeed, the representation of communities is often the subject of the research and/or the creative project. The making activity complicates the expected research conventions of anonymity, and also complicates the expectations of a (Euro-Western university-educated) maker community used to the individualised ownership of creative output. Articles presented here tackle these assumptions and show clearly how embedded participants can often be in the research context and questions, which in turn indicates how to tackle issues of (re)presentation. For example, Jacobs' study, which is set in the Sinai peninsula where cultural norms prevent women from independently stepping forward in public, subtly balances the cultural expectations for the individuals with whom she worked by commissioning an embroidered map as a product and citing the group collectively. In instances where the subject of research is highly sensitive, as with the Teal Quilt Project discussed by MacDowell, the anonymity of each survivor of sexual abuse for whom a quilt is made is crucial. The maker-participants involved in the project negotiated this through the careful selection of patchwork patterns and/or colours in their materials in lieu of naming individuals and explicit representation of their experiences. The Teal Quilt Project also raises interesting questions around the ownership of these works, made collectively by one community and intended for a different group of recipients. These quilts introduce the notion of the artwork as a gift, whereby the maker-participants renounce their individual claim to the work as material object yet retain their ownership of the gesture of participation and donation.

Conversely, the Emotional Fit project, presented by Townsend and Sadkowska, involves participants as both research subjects and co-researchers, demonstrating a model of practice that highlights a 'learning with' participants. Participants here are involved with both the presentation of the research 'findings' (in this case, the co-designed garment collection) at the Emotional Fit: Fashion Salon event, and in the representation of their participation in the project. Whilst this is a welcome development in participatory research practices, any claim to shared ownership must be dependent on the fully informed engagement of participants desiring this outcome.

\section{Innovation}

The question of innovation in these approaches to doing research is interesting. Within an art and design research context, innovation is often coupled with the creative invention of 
new products, materials, tools and processes. However, we are finding that a definition of innovation within a social making context needs to be broader and must foreground the experiential aspect of participatory textile making. Innovative approaches to undertaking research may build the investigation around the experiences and processes of textile designing and making, illustrated here in particular by the development of a new participatory model of practice by Townsend and Sadkowska, as outlined above. It is also and importantly - in acknowledging the experience of the participants in the project that innovative learning beyond the research takes place.

Innovation for participants might include the enabling of concrete learning, i.e. the learning of new skills. Taylor et al. present an example of this with the HUGs® social manufacturing project. Innovation may also, more humbly, consist of the creation of a reflective space for personal learning: an experience whereby the making activity allows time and space to gain insights into who you are. In this frame, the reflective space for personal learning created by the reciprocal nature of making together in Rana's study leads to both increased selfawareness for the participants and innovative research findings. Rana proposes that whereas the majority of studies around crafting in health contexts focus on the benefits of crafting for the care receiver, her research into dyadic crafting demonstrates ways in which making together can offer a therapeutic experience for both care receiver and care giver, particularly in non-institutional settings.

For Jacobs, on the other hand, the innovation in her study is the introduction of textile making into an otherwise audio-visual sphere. As a filmmaker exploring alternative mapping methods in the Sinai peninsula, she found that using film to document the tribes' navigation over the lands gave her access only to men's stories. The cultural norms surrounding interactions with women prevented women from stepping forward for their accounts to be filmed. Unsatisfied with this male-only perspective, she turned to embroidery as a means of accessing and documenting the women's stories. Once again, we see the potential for innovation by acknowledging the vulnerabilities of a particular research space.

\section{Conclusion}

As we conclude this second part of the Stitching Together double issue it is timely to acknowledge the vulnerabilities and limitations of this work. The positive and transformative potential of participatory textile making activities for participants and organisations - whether as creative practice or in the context of research - are now well documented ${ }^{4}$. However, as we continue to develop, diversify and strengthen these highly productive, yet frequently 
complex, approaches to research, there are still assumptions to be challenged, such as who can participate, and even whether participation is desirable. Sensitivity to the ethical dimensions of participation is crucial for co-produced knowledge in, about and for communities to be of value (Goodson and Phillimore 2012).

Another major output from the network's activities, the Stitching Together Good Practice Guidelines, aims to support facilitators of participatory textile making workshops and projects to develop and exercise such sensitivity by providing guidance on both ethical and practical aspects. Given the diversity of contexts within which participatory textile making occurs, there cannot be a single 'right' way to run a workshop or project, and this is reflected in the flexible language and format of the guidelines. Various issues are highlighted for consideration within each of the eight sections, which range from 'Getting Started' to 'Aftercare'; it is up to the facilitator to judge how relevant each one is to their particular context, and how they might respond. Our hope is that this adaptable structure provides a foundation for further discussion and allows for continued innovation. ${ }^{5}$

Despite the insights offered within the variety of case studies gathered in this double issue, which we are sure will have great value for those seeking to undertake research through participatory textile making activities, there are - of course - many questions still to be addressed. For instance, we might ask how the evolving legacy of textile projects can remain accessible for the multiple stakeholders, bearing in mind that a project's transformative potential may not primarily reside within the material artefact that is created. Answering questions such as these will require further collaboration, reflection and innovation - for example, by working more closely with grassroots organisations and developing textile making projects into longitudinal studies to gain deeper insights into the impacts of participation over the long term. We look forward to seeing how the interdisciplinary community of researchers and practitioners who 'stitch together' will collaboratively interrogate these questions in the future.

\section{Acknowledgements}

'Stitching Together' is funded by a research networking grant from the Arts and Humanities Research Council: grant reference AH/R007497/1.

Our grateful thanks to all the participants at the second Stitching Together networking event held in July 2019: 
Professor Ele Belfiore, Dr Stephanie Bunn, Eilish Clohessy, Katie Hill, Professor Rebecca Earley, Deirdre Figueiredo, Dr Katie Gaudion, Dr Emilie Giles, Rachael Matthews, Dr Jonathan Price, Sarah Redmond Fareham, Katie Smith, Rhian Solomon, Dr Nicola Thomas, Dr Katherine Townsend, Professor Janet van der Linden.

\section{References}

Clarke, N. A. (2020), 'Exploring the Role of Sewing as a Leisure Activity for Those Aged 40 Years and Under', TEXTILE, 18:2, pp. 118-144, doi: 10.1080/14759756.2019.1613948.

Corkhill, B., Hemmings, J., Maddock, A. and Riley, J. (2014), 'Knitting and Well-being', TEXTILE, 12:1, pp. 34-57, doi: 10.2752/175183514x13916051793433.

Dupré, F. (2008), 'Making stuff', Axis Dialogue, London: Axis, http://axiswebmedia.blob.core.windows.net/www/usermedia/103684/work/204094/vvwxlsvou ggj46xenikhw.pdf. Accessed 16 September 2020.

Freeman, J. (1997), 'Revering things or cherishing people: some professional and popular approaches to constructing craft communities', in: T. Harrod (ed.) Obscure Objects of Desire: Reviewing the Crafts in the Twentieth Century, University of East Anglia, 10-12 January 1997, London: Crafts Council, pp. 267-274.

Goodson, L. and Phillimore, J. (eds.) (2012), Community Research for Participation: From Theory to Method, Bristol: Policy Press.

Hackney, F., Maughan, H., and Desmarais, S. (2016), 'The Power of Quiet: Re-making Affective Amateur and Professional Textiles Agencies', Journal of Textile Design Research and Practice, 4:1, 33-62, doi: 10.1080/20511787.2016.1256139.

Hamalainen, M. and Karjalainen, J. (2017), 'Social Manufacturing: When the maker movement meets interfirm production networks', Business Horizons, 60 pp. 795-805.

Harrison, K. and Ogden, C. A. (2020), 'Knit "n" natter': A feminist methodological assessment of using creative 'women's work' in focus groups, Qualitative Research. ISSN 1468-7941, doi: https://doi.org/10.1177/1468794120945133.

Kara, H. (2018), Research Ethics in the Real World, Bristol: Policy Press.

Kettley, S., Sadkowska, A. and Lucas, R. (2016), 'Tangibility in e-textile participatory service design with mental health participants', in: Design Research Society, $50^{\text {th }}$ Annivesary Conference, University of Brighton, 27-30 June 2016.

https://static1.squarespace.com/static/55ca3eafe4b05bb65abd54ff/t/5752cfa08a65e246000 b79e8/1465044897471/488+Kettley.pdf. Accessed 16 September 2020.

Lindström, K. and Ståhl, A. (2010), 'Threads - A Mobile Sewing Circle: Making Private Matters Public in Temporary Assemblies', in: PDC'10, Proceedings of the $11^{\text {th }}$ Biennial Participatory Design Conference, Sydney, Australia, 29 November - 3 December 2010, pp. 121-130, https://doi.org/10.1145/1900441.1900459. 
Nickell, K. (2015), "Troubles Textiles": Textile Responses to the Conflict in Northern Ireland, TEXTILE, 13:3, pp. 234-251, doi: 10.1080/14759756.2015.1084693.

Pajaczkowska, C. (2005), 'On Stuff and Nonsense: The Complexity of Cloth', TEXTILE, 3:3, pp. 220-249, doi: 10.2752/147597505778052495.

Shercliff, E. and Twigger Holroyd, A. (2020), 'Stitching Together: Participatory textile making as an emerging methodological approach to research', Journal of Arts \& Communities, 10:1\&2, pp. 5-18, doi: https://doi.org/10.1386/jaac 000021.

Shercliff, E. and Twigger Holroyd, A. (2016), 'Making with others: Working with textile craft groups as a means of research', Studies in Material Thinking, 14,

https://www.materialthinking.org/sites/default/files/papers/0176_SMT_V14_P07_FA.pdf. Accessed 16 September 2020.

\footnotetext{
1 The Stitching Together research network, which is funded by the UK's Arts and Humanities Research Council, runs from January 2019 to June 2021. It is led by Dr Emma Shercliff (Arts University Bournemouth) and Dr Amy Twigger Holroyd (Nottingham Trent University).
}

2 Our use of the term is inspired by June Freeman's definition of 'person-oriented' approaches to craft as work that cherishes people, rather than objects (Freeman 1997).

${ }^{3}$ The second Stitching Together network event was a critical reflection workshop involving researchers, professional textile practitioners, project commissioners and 'critical friends' which took place in July 2019 at the Arts University Bournemouth, and which aimed to investigate the ethical, innovative and impactful dimensions of these new methodological approaches.

${ }^{4}$ For more case studies of participatory textile making activities see the first part of the Stitching Together special edition of the Journal of Arts and Communities: volume 10 issues 1\&2, published May 2020. For examples of textile craft and community activism see TEXTILE: Journal of Cloth and Culture: volume 14 issue 1, a special edition dedicated to Crafting Community edited by Kirtsy Robertson and Lise Vinebaum in 2016. See also Corkhill et al. 2014; Dupre 2008; Hackney, Maughan and Desmarais 2016; Kettley, Sadkowska and Lucas 2016; Lindström and Ståhl 2010; Nickell 2015; Harrison and Ogden 2020; Shercliff and Twigger Holroyd 2016.

${ }^{5}$ Stitching Together Good Practice Guidelines: Advice for facilitators of participatory textile making workshops and projects is available to download from the network website: stitchingtogether.net. 